\title{
Evaluating the Potential of Biodiesel Production through Microalgae Farming in Photobioreactor and High Rate Ponds from Wastewater Treatment
}

\author{
David M. M. Pinho, ${ }^{a}$ Renato S. Oliveira, ${ }^{a}$ Vitor M. L. dos Santos, ${ }^{a}$ Welington F. Marques, ${ }^{a}$ \\ Angelo C. Pinto, ${ }^{\dagger, b}$ Michelle J. C. Rezende ${ }^{b}$ and Paulo A. Z. Suarez ${ }^{*, a}$ \\ ${ }^{a}$ Laboratório de Materiais e Combustíveis (LMC), Instituto de Química, \\ Universidade de Brasília (UnB), 70904-970 Brasília-DF, Brazil \\ ${ }^{b}$ Instituto de Química, Universidade Federal do Rio de Janeiro (UFRJ), \\ 21044-020 Rio de Janeiro-RJ, Brazil
}

\begin{abstract}
In the last decade, the research works on microbial as a potential source of lipid for biodiesel production have been growing. In this work, the potential of a sludge from high-rate lagoons in urban sewage treatment, composed mainly by Chlorella sp., as oil source for biodiesel production, was studied. The potential of Chlorella sp. growth in photobioreactor under controlled conditions was also investigated. Low lipid content (up to 3\%) was observed in both cases. The composition of both oils showed high amount of fatty acids and fatty acid based compounds, however there are also other non-fatty acid based lipids. Density and viscosity of biodiesel from biosolid oil were determined and the results showed that these physico-chemical properties do not match the specification required for biodiesel. The results showed that sewage sludge from Samambaia treatment station (DF, Brazil) and Chlorella sp. cultivated under the conditions described in this work are not potential sources of fatty material for biodiesel production.
\end{abstract}

Keywords: Chlorella sp., microalgae, photobioreactor, biodiesel, sewage sludge

\section{Introduction}

Due to the strong dependence on fossil fuels, many countries have been thought alternative energy sources to solve fuel demand. In this context, biodiesel production has become an interesting option. ${ }^{1}$ For instance, in 2014, 3.42 billion liters of biodiesel were produced and used as liquid fuel in Brazil. It is worth mentioning that biodiesel production is still growing up in Brazil and the government is planning to double its use in the next years. ${ }^{2}$ However, the main raw material for biodiesel production in Brazil is the edible soybean oil (up to 80\%) and several criticisms have been done to this alternative energy source. Besides, vegetable oil is nowadays the main production cost of biodiesel (approximately 80\%). Thus, the search for other fatty material sources may avoid the trilemma food-energy-environment and make biodiesel a real sustainable liquid fuel.

Microalgae are undoubtedly an attractive biological option when it comes to capture and convert carbon dioxide

*e-mail: psuarez@unb.br

In memoriam into energy, as well as its industrial use in the capture of nutrients from wastewater. Indeed, microalgae have been pointed out as good source of carbohydrates and lipids to produce energy. From microalgal biomass, it can be extracted lipids to generate biodiesel and carbohydrates to ferment into bioethanol, as well as, it can be anaerobically fermented into biogas. ${ }^{3}$

Microalgae can be cultivated in open ponds or closed reactors with different designs. The oil productivity of microalgae is very controversial and different information can be found in the literature. For instance, $\mathrm{Chisti}^{4}$ has estimated the production of oil from microalgae and compared with the productivity of different agricultural crops, as can be seen in Table 1. However, it is worth to mention that no microalga farms have already started up for oil production. Indeed, the few microalga farms have been established for dietary supplements and cosmetics, such as encapsulated dried Chlorella or Spirulina strains, juices, etc. ${ }^{5,6}$ Besides, several issues of microalgae farming and processing lead to different results and it is possible to find oil content for the same strain varying from 5 to $70 \%$, as can be seen in Table 2 . 
Table 1. Oil productivity of some agricultural crops compared to estimated production using microalgae ${ }^{4}$

\begin{tabular}{lc}
\hline Source of biodiesel & Oil productivity / $\left(\mathrm{L} \mathrm{ha}^{-1}\right)$ \\
\hline Castor & 806 \\
Jatropha curcas & 1,892 \\
Corn & 172 \\
Soy & 446 \\
Canola & 1,190 \\
Coconut & 2,689 \\
Palma & 5,950 \\
Microalgae & $58,700^{\mathrm{a}}$ \\
\hline
\end{tabular}

aThis value was estimated by Chisti $^{4}$ from laboratory results.

Among the microalgae cultivated around the world, one of the most common is Chlorella sp. (unicellular algae), which has a known nutritional value, a big market and it is easy to produce. This is due to its natural tendency to dominate the environment in which it is found. It is worth mentioning that Chlorella sp. is one of the few microalgae that have commercialization in Brazil. ${ }^{7}$ Chlorella has been studied for a long time, being produced by more than 70 industries scattered around the world. The production is dedicated to human consumption, also, its world production reaches more than 2,000 t per year. ${ }^{8}$ Once again, it is important to highlight that all this production is used for dietary supplements and cosmetics and that there is no large scale oil extraction facility.

Besides, microalgae can be also obtained during wastewater treatment when the technology of high-rate lagoons is used. The high reproduction rate of microorganisms, such as microalgae and cyanobacteria, promotes the purification of the water consuming its organic load, and, thus, the produced biomass is separated by chemical and physical processes. Currently in Brazil, the destination of this biomass is the incineration, or more frequently its disposition in sanitary landfills. In other countries, this reality is not different. For example, the annual production of flax in the European Union and China is close to $11,000,000$ and $6,000,000$ tonnes, respectively. ${ }^{9}$ Considering that $50 \%$ of the cost of sewage treatment represent the treatment of this waste, it is necessary to use it in a sustainable manner aiming at reducing costs and environmental impact, thus completing a relationship between water treatment technologies and the environment.

The aim of this work was to evaluate the potential of microalgae farming in photobioreactors and highrate lagoons for biodiesel production. Indeed, we have isolated and characterized two different lipid samples and evaluated these materials in biodiesel production. Another aspect of this work was to evaluate the composition of the fatty material obtained from these two microalgae and its implication in specification of the obtained biodiesel as described in the Brazilian National Agency of Petroleum, Natural Gas and Biofuels (ANP) regulation.

\section{Experimental}

\section{Cultivation of the microalgae Chlorella sp.}

The microalga strain used in this study was Chlorella sp., provided by UTEX The Culture Collection of Algae, University of Texas (Austin, USA). The strain inoculum was prepared in an incubator with refrigeration and agitation (shaker). The strain was inoculated in Erlenmeyer, and after 4 weeks, the microalga culture was transferred to the Infors HT Labfors photobioreactor, model 5 Lux with

Table 2. Oil content of several species of microalgae ${ }^{6}$

\begin{tabular}{lccc}
\hline Microalga & Oil content / \% of dry weight & Microalga & Oil content / \% of dry weight \\
\hline Botrycoccus braunii & $25-75$ & Neochlorisole oabundans & $35-54$ \\
Chlorella sp. & $28-32$ & Nitzschia sp. & $16-47$ \\
Chlorella vulgaris & $5-58$ & Phaeodactylum tricornutum & $20-30$ \\
Cripthecondinium cohnii & 20 & Porphiridium cruentum & $9-19$ \\
Cylindrotheca sp. & $16-37$ & Scenedesmus obliquus & $11-55$ \\
Dunaliella primolecta & 23 & Scenedesmus sp. & $20-21$ \\
Dunaliella tertiolecta & $17-71$ & Schizochytrium sp. & $50-77$ \\
Euglena gracilis & $14-20$ & Spirulina maxima & $4-9$ \\
Isochrisis sp. & $25-33$ & Spirulina platensis & $4-16$ \\
Monallanthus salina & $>20$ & Tetraselmis suecica & $15-23$ \\
Nannochloris sp. & $20-35$ & Tetraselmis sp. & $13-15$ \\
Nannochloropsis sp. & $31-68$ & &
\end{tabular}


2.5 L glass vessel. Figure 1 shows the system in which the microalgae grew under controlled conditions.

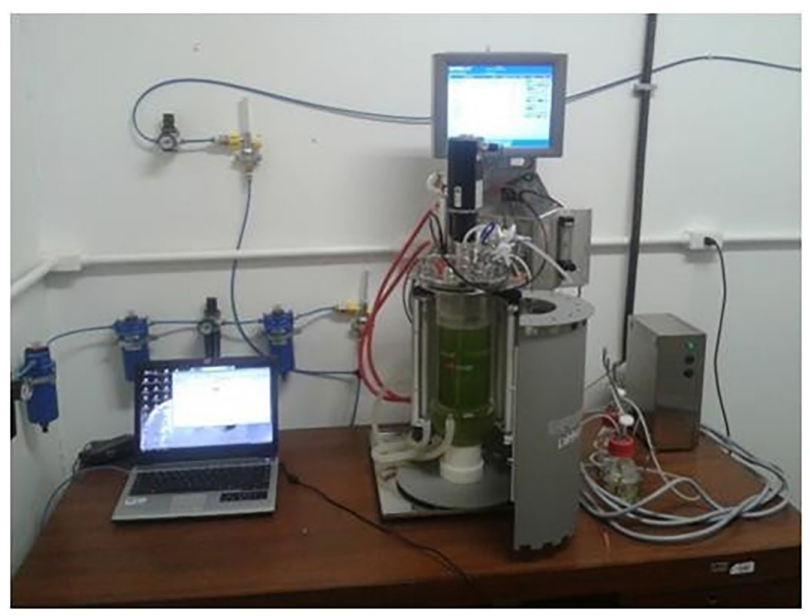

Figure 1. Photobioreactor. Source: Laboratório de Materiais e Combustíveis (LMC), Instituto de Química, UnB, 2014).

Three batches were performed using BG-11 medium in three different culture conditions: (i) standard nitrogen content BG-11SN (see Table 3); (ii) with double nitrogen content BG-11DN (3 $\mathrm{g}$ of $\mathrm{NaNO}_{3}$ ); and (iii) with no nitrogen BG-11NN (no $\mathrm{NaNO}_{3}$ added). The glass vessel of the photobioreactor with the culture medium was sterilized in an autoclave for $15 \mathrm{~min}$ at a pressure of $120 \mathrm{~atm}$.

The following parameters were controlled in the photobioreactor: luminosity, aeration, temperature and $\mathrm{pH}$. The light was obtained by the light chamber of the photobioreactor, in which, during the incubation period, the algal biomass developed in a photoperiod of direct light. ${ }^{11}$ The luminosity was achieved by means of fluorescent lamps of a total of $48 \mathrm{~W}$ in photoperiod of $24 \mathrm{~h} / 24 \mathrm{~h}$ until the growth stabilization. The aeration was obtained by continuous air injection using the compressor Pratic Air Schulz model CSI 7,4 (125 ibf pulg-2, $50 \mathrm{~L}$,

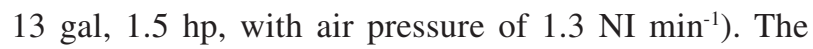
temperature was measured by means of a sensor coupled to the reactor, being around $27{ }^{\circ} \mathrm{C}$. The $\mathrm{pH}$ value was stabilized at 7.0 and measured with a mobile $\mathrm{pH}$-meter coupled to the reactor. Both $\mathrm{pH}$ and temperature were based on previous studies with microalgae, in which close values were optimized, about 25 to $30{ }^{\circ} \mathrm{C}$ for temperature, and 7.0 to 8.0 for $\mathrm{pH} .{ }^{12}$ The $\mathrm{pH}$ value was controlled by acid/ alkaline solutions. These solutions were injected into the closed system of the reactor through the sterilized hoses connected to the reactor, avoiding contamination of the culture medium. All parameters were monitored daily to control the growth of algal biomass.

The material was decanted at the end of the batch. The supernatant was discarded and the biomass dried in an oven at $60^{\circ} \mathrm{C}$.

\section{Sample of sewage sludge}

The material was collected in a single time at Samambaia sewage treatment station, located on the banks of DF-180 highway, $\mathrm{km} \mathrm{42.} \mathrm{This} \mathrm{treatment} \mathrm{station} \mathrm{serves}$ the cities of Samambaia and Taguatinga (DF, Brazil). The sewage sludge was dried by exposing the sample to room temperature until it showed solid appearance, even when crushed. After drying, the material was called biosolid, and then ground in a semi-industrial hammer mill until it passed through a $2.5 \mathrm{~mm}$ sieve.

Table 3. BG-11 medium preparation (adapted from reference 10)

\begin{tabular}{|c|c|c|c|}
\hline Nutrient & Reagent & Concentration / $\left(\mathrm{g} \mathrm{L}^{-1}\right)$ & $\begin{array}{l}\text { Quantities added to the reactor per } \mathrm{L} \\
\text { of medium }\end{array}$ \\
\hline \multirow{4}{*}{ Stock solution 1} & $\mathrm{Na}_{2} \mathrm{Mg}$ EDTA & 0.1 & \multirow{4}{*}{$10 \mathrm{~mL}$} \\
\hline & ferric ammonium citrate & 0.6 & \\
\hline & $\mathrm{C}_{6} \mathrm{H}_{8} \mathrm{O}_{7} \cdot 1 \mathrm{H}_{2} \mathrm{O}$ & 0.6 & \\
\hline & $\mathrm{CaCl}_{2} \cdot 2 \mathrm{H}_{2} \mathrm{O}$ & 0.6 & \\
\hline Stock solution 2 & $\mathrm{MgSO}_{4} \cdot 7 \mathrm{H}_{2} \mathrm{O}$ & 7.5 & $10 \mathrm{~mL}$ \\
\hline \multirow{2}{*}{ Stock solution 3} & $\mathrm{~K}_{2} \mathrm{HPO}_{4} \cdot 3 \mathrm{H}_{2} \mathrm{O}$ & 4.0 & \multirow[t]{2}{*}{$10 \mathrm{~mL}$} \\
\hline & or $\mathrm{K}_{2} \mathrm{HPO}_{4}$ & 3.05 & \\
\hline \multirow{7}{*}{ Stock solution 4} & $\mathrm{H}_{3} \mathrm{BO}_{3}$ & 2.86 & \multirow{7}{*}{$1 \mathrm{~mL}$} \\
\hline & $\mathrm{MnCl}_{2} \cdot 4 \mathrm{H}_{2} \mathrm{O}$ & 1.81 & \\
\hline & $\mathrm{ZnSO}_{4} \cdot 7 \mathrm{H}_{2} \mathrm{O}$ & 0.222 & \\
\hline & $\mathrm{CuSO}_{4} .5 \mathrm{H}_{2} \mathrm{O}$ & 0.079 & \\
\hline & $\mathrm{COCl}_{2} \cdot 6 \mathrm{H}_{2} \mathrm{O}$ & 0.050 & \\
\hline & $\mathrm{NaMoO}_{4} \cdot 2 \mathrm{H}_{2} \mathrm{O}$ & 0.391 & \\
\hline & or $\mathrm{MoO}_{4}(85 \%)$ & 0.018 & \\
\hline Solid 1 & $\mathrm{Na}_{2} \mathrm{CO}_{3}$ & - & $0.02 \mathrm{~g}$ \\
\hline Solid 2 & $\mathrm{NaNO}_{3}$ & - & $1.50 \mathrm{~g}$ \\
\hline
\end{tabular}


Organic fraction study of biosolid

A sample of $10 \mathrm{~g}$ of biosolid was dried in an oven at $100{ }^{\circ} \mathrm{C}$ for $24 \mathrm{~h}$. After this period, the sample was cooled in a desiccator and weighed. This process was repeated until there was no loss of mass between two periods. The inorganic fraction was quantified after heating $1 \mathrm{~g}$ of biosolid in a porcelain crucible at $700{ }^{\circ} \mathrm{C}$ for $30 \mathrm{~min}$. The procedure was also carried out until constant weight. The organic matter content was then determined by the difference between the initial biosolid mass and the inorganic matter content.

\section{Extraction of the lipids present in the biomass of Chlorella sp. and biosolid}

The AOCS (American Oil Chemists' Society) Ae 3-52 standard method was used in the lipid extraction since it allows the quantification of the lipid material by the difference in mass of the material before and after extraction. In this method, the solvent promotes the extraction using Soxhlet apparatus. The cartridge used to accommodate the sample in the Soxhlet was prepared following AOCS Aa 4-38 standard method.

\section{Preparation of biodiesel from Chlorella sp. and biosolid}

The lipid material extracted from the sewage sludge was acidified by the addition of hydrochloric acid and water, under reflux at $80{ }^{\circ} \mathrm{C}$ for $8 \mathrm{~h}$. Then, the material was washed several times with distilled water until the $\mathrm{pH} 5$ of the wash water.

The esterification was carried out mixing the Chlorella sp. oil or the acidified biosolid oil, sulfuric acid and methanol, and keeping the mixture under reflux at $80{ }^{\circ} \mathrm{C}$ for $4 \mathrm{~h}$. This reaction is repeated several times until the yield in fatty acid methyl esters is greater than $95 \%$. The quantification of the yield in fatty acid methyl esters was determined by two different methods: (i) when using acidified biosolid oil, it was analyzed the reduction of the acid value in comparison to the starting material. The acid number was determined according to AOCS Cd 3d-63 standard method; (ii) when using Chlorella sp. oil, it was analyzed the final composition of the sample by high performance liquid chromatography (HPLC) using a method published elsewhere. ${ }^{13}$

The reaction was followed up by Fourier transform infrared spectroscopy (FTIR) and $1 \mathrm{H}$ nuclear magnetic resonance $\left({ }^{1} \mathrm{H}\right.$ NMR). FTIR was obtained using a Shimadzu Prestige-21 equipment, with an attenuated total reflectance (ATR) cell, $7 \mathrm{~mm}$ optical path and 10 reflections, using a nominal spectral resolution of $4 \mathrm{~cm}^{-1}$ and 32 scans. ${ }^{1} \mathrm{H}$ NMR spectra were obtained in a Bruker Advance III HD $600 \mathrm{MHz}$ equipment, using $\mathrm{CDCl}_{3}$ as solvent and chemical shifts were reported in ppm relative to tetramethylsilane (TMS).

\section{HPLC analysis}

This analysis was carried out on a Shimadzu model CTO-20A with an ultraviolet detector (UV-VIS) equipment using a Shim-Pack VP-ODS column (C18, 250 (long) $\times 4.6 \mathrm{~mm}$ (internal diameter)). The oven temperature was maintained at $40{ }^{\circ} \mathrm{C}$ during the analysis. The injection samples were prepared by mixing $25 \mu \mathrm{L}$ of the sample and $2 \mathrm{~mL}$ of the column eluent. The analysis was conducted following a method described in the literature. ${ }^{13}$ The solvent gradient consists of $100 \%$ methanol and $0 \%$ isopropanol/hexane $(5: 4, \mathrm{v}: \mathrm{v})$ in $0 \mathrm{~min}$. The concentration of the isopropanol/hexane mixture $(5: 4 \mathrm{v}: \mathrm{v})$ gradually increases until $10 \mathrm{~min}$ of analysis when it reaches 50:50 v:v with methanol, maintaining the mixture up to $17 \mathrm{~min}$, when methanol is raised again to $100 \%$ up to $23 \mathrm{~min}$, finishing the analysis. ${ }^{13}$ The solvent flow was $1 \mathrm{~mL} \mathrm{~min}^{-1}$, and it was injected $10 \mu \mathrm{L}$ of the sample.

Inductively coupled plasma-atomic emission spectrometry (ICP-AES)

The identification and quantification of mineral composition in the biosolid was performed in an ICP-OES equipment (iCAP 6000 Series), Thermo Fischer Scientific, Cambridge, United Kingdom. The source was argon, with a flow of $0.5 \mathrm{~L} \mathrm{~min}^{-1}$ for the aqueous method and $1.5 \mathrm{~L} \mathrm{~min}^{-1}$ for the organic method. The calibration curve was done with a standard containing 24 elements, all curves had $\mathrm{R}^{2}$ (coefficient of determination) higher than 0.9999, in both the organic and the aqueous method, with the exception of silicon in the aqueous method ( $\mathrm{R}^{2}$ was 0.9360$)$. The sample was prepared by weighing $0.01 \mathrm{~g}$ of the biosolid and diluted in $3.8 \mathrm{~g}$ of kerosene to the organic sample and digestion in water for the aqueous sample.

Analysis of biodiesel samples from biosolid and Chlorella sp. oils by GC-MS-FID

The biodiesel samples were prepared at the concentration of $1 \mathrm{mg} \mathrm{mL}^{-1}$ in ethyl acetate. The samples were analyzed by gas chromatography with simultaneous detection by flame ionization detector and mass spectrometry (GC/MS-FID). ${ }^{14}$ The analyzes were performed on a Shimadzu GC-QP2010 chromatograph containing a flow splitter for different detectors, a flame ionization detector (FID) and a GCMS-QP2010 mass spectrometer (MS). The mass spectrometer has a $70 \mathrm{eV}$ electron ionization source and 
a single quadrupole analyzer with electron multiplier detector. The capillary column was RXi-1MS (100\% methyl polysiloxane), $30 \mathrm{~m}$ (long) $\times 0.25 \mathrm{~mm}$ (internal diameter) $\times 0.25 \mu \mathrm{m}$ (phase thickness). The carrier gas was helium 4.5 (99.995\% purity) at a flow rate of $1.8 \mathrm{~mL} \mathrm{~min}^{-1}$. The injection volume was $1.0 \mu \mathrm{L}$, in split mode and with 1:10 split ratio. A non-depressed straight glass liner with a volume of $990 \mu \mathrm{L}$ was used.

The oven temperature setting was: initial temperature of $120^{\circ} \mathrm{C}$ for $2 \mathrm{~min}$, followed by heating rate of $12^{\circ} \mathrm{C} \mathrm{min}^{-1}$ to $210^{\circ} \mathrm{C}$, remaining at this temperature for $2 \mathrm{~min}$, followed by heating rate of $15^{\circ} \mathrm{C} \mathrm{min}^{-1}$ to $290^{\circ} \mathrm{C}$, and final isothermal period of $1 \mathrm{~min}$. The injector, the flame ionization detector and the mass spectrometer interface were held at $290{ }^{\circ} \mathrm{C}$. The ionization source was maintained at $250{ }^{\circ} \mathrm{C}$. SCAN mode was used in the mass range of 35 to $700 \mathrm{Da}$. The calibration used for the mass spectrometer was autotune. All compounds were tentatively identified by comparison with mass spectra of the NIST 11 mass spectral library with percent similarity of $80 \%$ or greater.

\section{Microscopy of the samples}

The samples were collected and placed on a slide for observation under optical microscope with coupled camera (magnification of up to $100 \times$ ). For the cell count, an optic mirror improved double Neubauer chamber was used, with a $0.1 \mathrm{~mm}$ chamber depth, divided into 25 square groups of $0.2 \mathrm{~mm}$ on each side. Each group consists of 16 mini-areas with $0.05 \mathrm{~mm}$ of each side (area of $0.0025 \mathrm{~mm}^{2}$ ).

The counting was performed in an optical microscope from Bioval model L2000C, being performed to obtain the cellular concentration per mL. For the counting, daily aliquots were taken in each batch, about $0.1 \mathrm{~mL}$, diluted in $0.9 \mathrm{~mL}$ of distilled water and added to the Neubauer chamber.

\section{Results and Discussion}

\section{Biomass production}

\section{Biosolid drying from sewage sludge}

Prior to biodiesel production, the oil had to be extracted from the sewage sludge. The sample was in situ collected and dried at sunlight exposure for 3 days. It was verified that the weight of the sample reduced to $6 \%$ of the initial mass of the sewage sludge collected in Samambaia treatment station. In Figure 2, the photographic image of the sewage sludge obtained in the treatment station can be visualized before and after drying.

In order to characterize the biota present in the biosolid, a slide was prepared with the sewage sludge and another

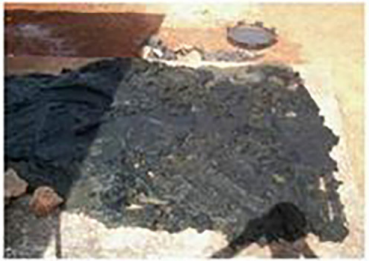

Before drying

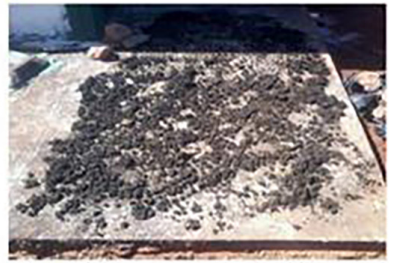

After drying
Figure 2. Images of the sewage sludge collected at Samambaia treatment station before and after drying.

with the strain Chlorella sp. Both samples were analyzed under an optical microscope. Photographs of the blades are shown in Figure 3. In the blade containing the algae Chlorella sp. (Figure 3a), a uniformity of the algae is observed, whereas in the blade containing sewage sludge (Figure 3b), a heterogeneity of the material is observed, indicating the presence of different species. The presence of green nodules similar to those observed on the lamina containing the algae Chlorella sp. indicates the possible presence of alga colonies in the sewage sludge.

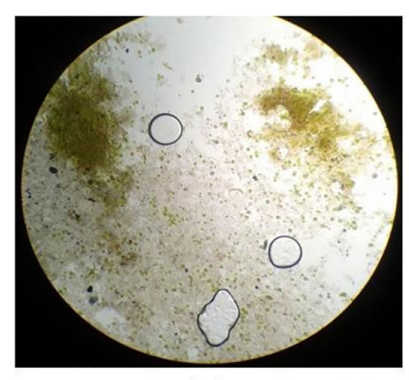

(a)

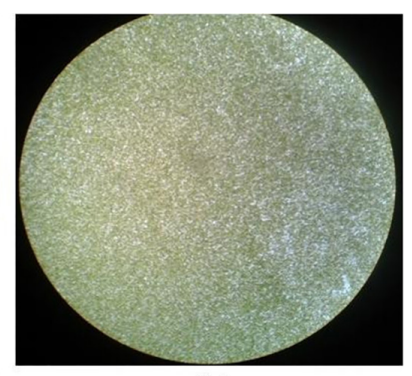

(b)
Figure 3. Blades containing algae Chlorella sp. (a) and sewage sludge (b).

The identification by microscopy showed the predominance of microalga groups Chlorophyta (Chlorella sp.) and Euglenophyta (Euglena sp. and Phacus sp.), for two samples analyzed (effluent in the high-rate lagoon and final lagoon effluent), as can be observed on Figure 4. This result was expected since the Euglenophyta group develops well in environments with high organic load because they are facultative heterotrophs. In the absence of light, this group consumes organic matter from the medium.

The composition of the biosolid was determined. It has $18 \% \mathrm{~m} / \mathrm{m}$ of volatiles at $100{ }^{\circ} \mathrm{C}$, probably water, $40 \% \mathrm{~m} / \mathrm{m}$ of organic material and $34 \% \mathrm{~m} / \mathrm{m}$ of minerals. Considering the biosolid without volatiles, the mineral fraction rises to $41 \% \mathrm{~m} / \mathrm{m}$.

The lipid content was determined using hexane as solvent (AOCS Ae 3-52 standard method) and it was very low, less than $0.5 \% \mathrm{~m} / \mathrm{m}$. Thus, the extraction was repeated using dichloromethane instead of hexane. Thereafter, the extraction reached $3 \% \mathrm{~m} / \mathrm{m}$ of lipid. A possible reason for 


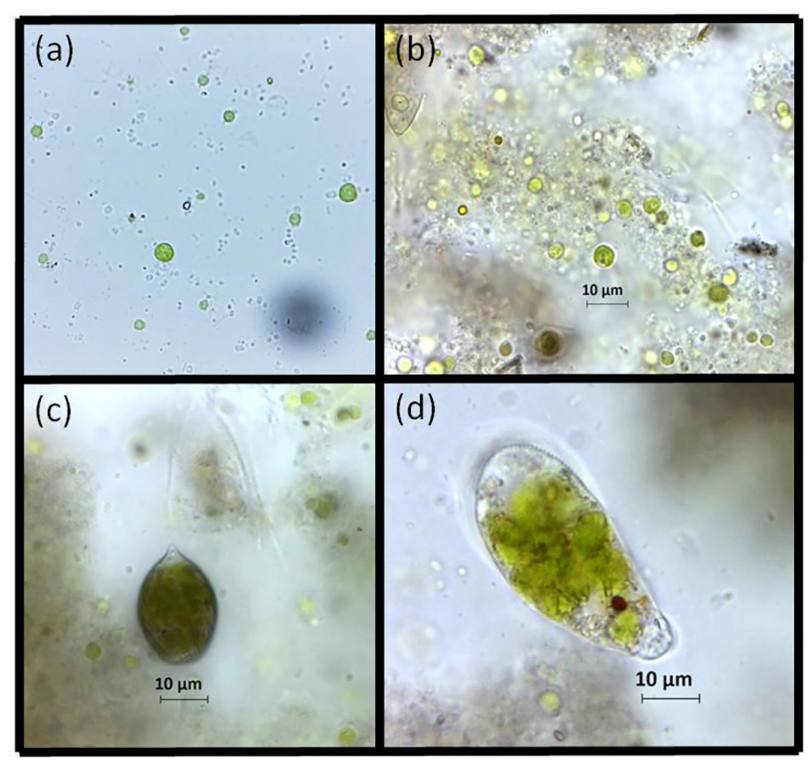

Figure 4. Identified biota in sewage sludge: (a) predominance of Chlorella sp. between the chlorophytes; (b) Chlorella sp. in the final sludge sample, with a diameter of approximately $5 \mathrm{~mm}$; (c) evidence of Phacus, from the phylum of Eugenophytes; and (d) evidence of Euglena, from the phylum of Eugenophytes.

this low lipid content could be the difficulty in breaking the alga cells, as related in the literature. ${ }^{15}$ Thus, the extraction was performed in an alternative mode by sonicating the biosolid with the solvent for $10 \mathrm{~min}$. This procedure was repeated three times using the same biosolid but a new volume of solvent. After analyzing the oil content, it was observed the same result $(3 \% \mathrm{~m} / \mathrm{m})$.

Since the amount of material extracted is very low, the extraction was carried out successively in order to obtain sufficient volume of material to the production of biodiesel. The following extractions were carried out with a $1: 1$ hexane/dichloromethane mixture in order to have greater extraction control and less solvent losses, as the vapor pressure of dichloromethane (BP (boiling point) $39^{\circ} \mathrm{C}$ ) is extremely high compared to hexane (BP $68{ }^{\circ} \mathrm{C}$ ).

To evaluate the mineral content of biosolid, it was determined the metal content present in the material, and the results are presented in Table 4. As can be seen, a large number of elements was found in the solid and few of them are dissolved in the oil. Note that the elements found in the biosolid are commonly present in domestic sludge or used in its treatment. Thus, this composition was already expected since the sewage treated in the Samambaia treatment station is a domestic sewage from Samambaia region.

\section{Chlorella sp. cultivation in photobioreactor}

From the tested conditions, the highest cell concentration was observed using the BG-11SN condition, while in the
Table 4. Composition of mineral material in the biosolid

\begin{tabular}{lcc}
\hline Metal & Biosolid / ppm & Oil / ppm \\
\hline $\mathrm{Al}$ & 3444 & - \\
$\mathrm{Fe}$ & 36 & 260 \\
$\mathrm{~K}$ & 14194 & - \\
$\mathrm{Mg}$ & 4367 & - \\
$\mathrm{P}$ & 3707 & 48 \\
$\mathrm{~S}$ & 32539 & - \\
$\mathrm{Si}$ & 10582 & 1440 \\
$\mathrm{Sn}$ & 216 & - \\
\hline
\end{tabular}

BG-11NN, a short decline in the cell population was observed after the first day of cultivation. Growth curves can be observed in Figure 5. The amount of obtained biomass is strongly dependent to the cellular metabolism of these microorganisms, as well as its growth conditions. ${ }^{16-18}$ The decline in the population in the BG-11NN medium was caused by the unavailability of nitrogen, an essential nutrient in the constitution of proteins and nucleic acids, as well as being a component of a molecule essential for the maintenance of the life of all organisms in the biosphere.

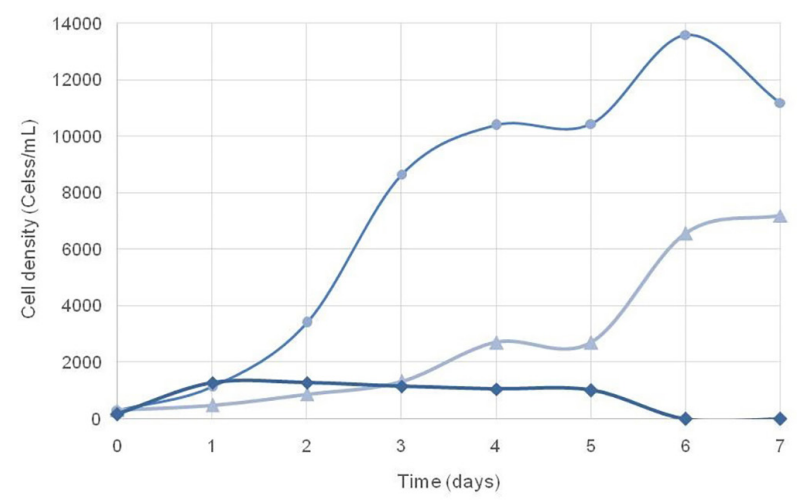

Figure 5. Growth curves of Chlorella sp. in different nitrogen content medium: $(\bullet)$ BG-11SN, ( $\Delta$ ) BG-11DN and BG-11NN $(\bullet)$.

About $2 \mathrm{~L}$ of algal culture were obtained as final product in the photobioreactor, under different conditions. After decanting, $300 \mathrm{~mL}$ of the biomass were recovered and oven-dried. The final dried biomass varied according to the medium used: $2.7 \mathrm{~g}$ for BG-11SN, $2.4 \mathrm{~g}$ for BG-11DN and $0.7 \mathrm{~g}$ for BG-11NN. Considering that the photobioreactor has a volume of $2 \mathrm{~L}$, this means a production of $1.35,1.2$ and $0.35 \mathrm{~g} \mathrm{~L}^{-1}$ of dry biomass. This is a very good result, as it is observed in the literature that the biomass production does not exceed $1 \mathrm{~g} \mathrm{~L}^{-1} \cdot{ }^{19,20}$

The condition of blue green medium (BG-11SN) was shown to be more efficient for biomass growth. There is a study in the literature that tested different means of 
cultivation of Chlorella, and the authors found greater production of biomass, about $0.82 \mathrm{~g} \mathrm{~L}^{-1}$ in BG-11 medium. ${ }^{21}$ The study also observed the effect of nitrogen compounds in the effluent and in the standard BG-11 culture medium, and it found a higher concentration of nitrate ion in the standard BG-11 medium. The BG-11 culture medium is characterized by high nitrate concentration and low phosphorus concentration and, therefore, these factors have great importance to microalgae growth and biomass production. ${ }^{22}$

Algal oil content resulted in an average of $0.041 \mathrm{~g}$ for BG-11SN, $0.030 \mathrm{~g}$ for BG-11DN and $0.024 \mathrm{~g}$ for BG-11NN1, representing $1.50,1.25$ and $3.43 \% \mathrm{~m} / \mathrm{m}$, respectively. Although the low biomass and oil production using the three medium, it becomes clear that under nitrogen-free conditions, the oil content in the biomass is twice the amount observed for algae growing in the presence of nitrogen.

\section{Lipid characterization and biodiesel production}

Figure 6 shows the FTIR spectra of both lipids extracted from biosolid and Chlorella sp. As can be depicted from Figure 6, the FTIR spectrum of the algae oil shows the characteristic vibrations at $1740 \mathrm{~cm}^{-1}$, corresponding to stretch of the $\mathrm{C}=\mathrm{O}$ ester bonds, and at 3012, 2923 and $2852 \mathrm{~cm}^{-1}$, corresponding to the $\mathrm{C}-\mathrm{H}$ of the aliphatic chains and an absorption at $1709 \mathrm{~cm}^{-1}$ corresponding to $\mathrm{C}=\mathrm{O}$ stretch of carboxylic acids, evidencing some hydrolysis of the oil. The FTIR spectrum of biosolid oil shows no band at $1740 \mathrm{~cm}^{-1}$, but absorptions at 1709, 1673 and $1621 \mathrm{~cm}^{-1}$. These two new bands at 1673 and $1621 \mathrm{~cm}^{-1}$ probably are related to carboxylates and corroborate the high metal content of the oil observed by ICP. The absence of triacylglycerides in the biosolid oil was confirmed by ${ }^{1} \mathrm{H}$ NMR measurements, which evidenced the absence of

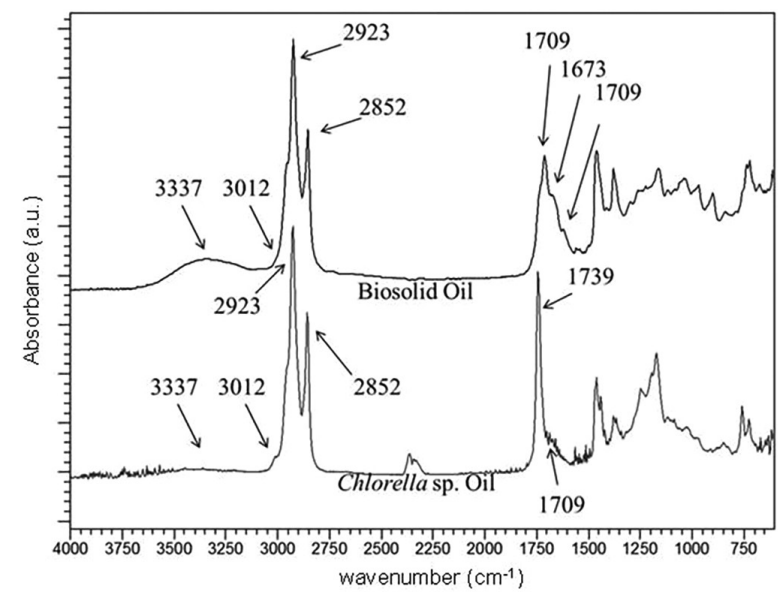

Figure 6. FTIR spectra of Chlorella sp. and biosolid extracted oils. signals in the region of 4-4.5 ppm relative to the hydrogens of glycerol (data not shown).

Due to the large quantity of soaps, biodiesel production from biosolid oil was not directly carried out via the esterification reaction. First, the oil was treated with hydrochloric acid for the conversion of carboxylates into carboxylic acids. After acidification, it was observed by FTIR the disappearance of the bands related to the carboxylate groups and the increase in the absorbance of bands related to carboxylic acids.

After acidification, the esterification reaction was carried out and the reaction yield was determined by titration, FTIR and ${ }^{1} \mathrm{H}$ NMR (data not shown). In the first esterification, it was observed only $75 \%$ of conversion. Thus, it was necessary four consecutive esterification steps in order to achieve conversions up to $96.5 \%$. By FTIR and ${ }^{1} \mathrm{H}$ NMR (data not shown) spectra, it was possible to confirm the conversion of the carboxylic acids in methyl esters.

Chlorella sp. biodiesel was obtained directly by esterification and the reaction yield was determined by HPLC, being also necessary four esterification steps in order to achieve conversions up to $96.5 \%$.

Both biodiesels from Chlorella sp. and biosolid oils were analyzed by GC/MS-FID and the data is presented in Table 5. The composition of both biodiesels is a mixture of several compounds, not necessarily of fatty acids methyl esters, such as the octadecane (entry 13, Table 5) present in the biodiesel of biosolid and a norbornene derivative (entry 1, Table 5) in the biodiesel of Chlorella sp. phytol acetate (entry 20, Table 5) was also found in both biodiesels and it is probably derived from chlorophyll. In addition to the identified peaks, other 18 peaks ranging from 0.1 to $2.2 \%$ of area could not be identified with a similarity of more than $80 \%$ in biodiesel produced from biosolid. In biodiesel from Chlorella sp., a total of 14 peaks could not be identified. These peaks account for 16.4 and $5.2 \%$ of the total area of the chromatogram of biosolid biodiesel and Chlorella sp. biodiesel, respectively, and are probably no usual fatty acid methyl esters.

From the results showed on Table 5, 93.9\% of the biodiesel of Chlorella sp. were composed by fatty acid methyl esters, while in biodiesel of biosolid this value $79.5 \%$. The difference in the composition of the oils occurs due to the different growth medium of the algae and also environmental interferers, which affect not only the fatty acid composition of the oil, but also the presence of other non-fatty acid lipids, as well stated in the microalgae literature. It is interesting to note that by ANP regulation, biodiesel should contain at least $96.5 \%$ of fatty acid methyl esters. Thus, because of the presence 
Table 5. Peaks identified from the GC/MS-FID a analysis of biodiesel from biosolid and Chlorella sp. oils

\begin{tabular}{|c|c|c|c|c|c|}
\hline \multirow{2}{*}{ entry } & \multirow{2}{*}{ Constituent $^{\mathrm{b}}$} & \multicolumn{2}{|c|}{ Chlorella sp. } & \multicolumn{2}{|c|}{ Biosolid } \\
\hline & & $\mathrm{t}_{\mathrm{R}}^{\mathrm{c}} / \mathrm{min}$ & Area $/ \%$ & $t_{R}{ }^{c} / \min$ & Area / \% \\
\hline 1 & norbornene derivative & 2.77 & 0.1 & - & - \\
\hline 2 & 9-oxo-nonanoate & 6.40 & 0.1 & - & - \\
\hline 3 & methyl dodecanoate & - & - & 7.66 & 0.4 \\
\hline 4 & dimethyl nonanoate diester & 7.70 & 0.1 & - & - \\
\hline 5 & methyl tridecanoate & - & - & 8.37 & 0.2 \\
\hline 6 & hexadecane & - & - & 8.67 & 0.6 \\
\hline 7 & octadecenal & - & - & 9.48 & 0.1 \\
\hline 8 & methyl tetradecenoate & - & - & 9.53 & 0.5 \\
\hline 9 & heptadecane & - & - & 9.70 & 0.9 \\
\hline 10 & methyl tetradecanoate & 9.76 & 0.3 & 9.77 & 3.2 \\
\hline 11 & methyl pentadecanoate & 10.48 & 0.1 & 10.49 & 3.2 \\
\hline 12 & methyl 12-methyl-tridecanoate & 10.57 & 0.1 & 10.58 & 1.6 \\
\hline 13 & octadecane & - & - & 10.83 & 0.9 \\
\hline 14 & methyl hexadecatetraenoate & 11.57 & 6.0 & - & - \\
\hline 15 & methyl hexadecatrienoate & 11.77 & 2.0 & - & - \\
\hline 16 & methyl hexadecenoate & 12.08 & 1.8 & 11.92 & 21.9 \\
\hline 17 & methyl hexadecanoate & 12.20 & 39.2 & 12.20 & 20.7 \\
\hline 18 & methyl heptadecanoate & - & - & 12.95 & 1.6 \\
\hline 19 & methyl 14-methyl hexadecanoate & 13.32 & 0.2 & 13.34 & 2.0 \\
\hline 20 & phytol acetate & 13.57 & 0.5 & 13.58 & 1.6 \\
\hline 21 & methyl octadecadienoate & 13.99 & 1.9 & 13.99 & 3.2 \\
\hline 22 & methyl octadecatrienoate & 14.04 & 22.7 & 14.04 & 1.7 \\
\hline 23 & methyl octadecenoate & 14.14 & 18.2 & 14.13 & 16.9 \\
\hline 24 & methyl octadecanoate & 14.33 & 1.7 & 14.35 & 2.1 \\
\hline
\end{tabular}

aGC/MS-FID: gas chromatography with simultaneous detection by flame ionization detector and mass spectrometry; ${ }^{\mathrm{b}}$ major constituents are shown in bold; ${ }^{\mathrm{c}} \mathrm{t}_{\mathrm{R}}$ : retention time.

of other lipid compounds different from fatty acid esters in both biodiesel obtained from microalgae and biosolid, the results do not match the ANP RANP No. 45/2014. ${ }^{23}$ As the separation of these lipid compounds is difficult, these oils probably cannot be considered as viable alternatives for the production of biodiesel.

It is possible to verify that biodiesel from Chlorella sp. oil and from biosolid oil has large amount of polyunsaturated and saturated chains. This composition may have also an effect on the physical-chemical properties of the biodiesel, as far as the saturated chains affect its cold properties and the presence of polyunsaturated ones reduces its oxidation stability. Furthermore, the presence of the other lipid compounds, such as octadecane and norbornene, may also affect the physico-chemical properties of the mixture.

In order to check the physico-chemical properties of biodiesel from biosolid oil, the density and viscosity of the products obtained in the first (biodiesel $75 \%$, entry 3 ,
Table 6) and fourth (biodiesel 96.5\%, entry 4, Table 6) steps of esterification of the acidified biosolid oil are determined. The results are presented in Table 6. It is also shown in Table 6 the density and viscosity of the biosolid oil, acidified biosolid oil and soybean biodiesel for comparison

Table 6. Density and viscosity of biosolid oil, acidified oil and products from biosolid oil esterification

\begin{tabular}{lccc}
\hline entry & Product & $\begin{array}{c}\text { Density / } \\
\left(\mathrm{g} \mathrm{cm}^{-3}\right)\end{array}$ & $\begin{array}{c}\text { Viscosity / } \\
\left(\mathrm{mm}^{2} \mathrm{~s}^{-1}\right)\end{array}$ \\
\hline 1 & biosolid oil & 999.5 & 97.7 \\
2 & acidified biosolid oil & 1009.5 & 566.5 \\
3 & biodiesel 75\% & 990.0 & 244.3 \\
4 & biodiesel 96.5\% & 989.2 & 120.5 \\
5 & soybean biodiesel & 883.3 & 2.8 \\
6 & ANP limit & $850-900$ & $3.0-6.0$ \\
\hline
\end{tabular}

ANP: Brazilian National Agency of Petroleum, Natural Gas and Biofuels. 
purposes. The limit allowed by ANP for biodiesel according to ANP RANP No. 45/2014 is also showed. It is worth to mention that Chlorella sp. biodiesel was not studied because its high methyl linolenate content makes this oil very unstable and susceptible to oxidation, leading to the formation of polymers and oxygen compounds in contact with air, and, thus, the data would be very unreliable. In Table 6, it is possible to observe that the density and the viscosity of the biodiesel with $96.5 \%$ of conversion (entry 4 , Table 6) do not match the specification required for this fuel. In addition, it can be observed that the acidified biosolid oil (entry 2, Table 6) has density and viscosity higher than biosolid oil, which is probably due to hydrogen bonding between carboxylic acid molecules.

\section{Conclusions}

Based on this research, it is possible to conclude that, although Chlorella sp. cultivation has shown to be viable in photobioreactor, the biomass content resulting from this process is low for an effective production of oil. It was also observed that the lipid content in the biosolid generated in the high-rate lagoons of Samambaia sewage treatment station is low. The amount of fatty acids in both bio oils was less than the minimum required by the specification of ANP. Particularly for the biodiesel from biosolid, the presence of other constituents leads to density and viscosity values that are not in agreement with the ANP specification. These results showed that sewage sludge from Samambaia treatment station and Chlorella sp. cultivated under the conditions described in this work are not potential sources of fatty material for biodiesel production.

\section{Acknowledgments}

The authors are in debt to CAPES, INCT-Catálise, CNPq and FAPDF for partial financial support. P. A. Z. S. thanks $\mathrm{CNPq}$ for research fellowship.

\section{References}

1. Guanhua, H.; Fengn, C.; Dong, W.; Xuewu, Z.; Gu, C.; Appl. Energy 2010, 87, 38.

2. Oliveira, F. C.; Coelho, S. T.; Renewable Sustainable Energy Rev. 2017, 75, 168.
3. Craggs, R. J.; Heubeck, S.; Lundquist, T. J.; Benemann, J. R.; Water Sci. Technol. 2011, 63, 660.

4. Chisti, Y.; Biotech. Adv. 2007, 25, 294.

5. Derner, R. B.; Ohse, S.; Villela, M.; Carvalho, S. M.; Fett, R.; Cienc. Rural 2006, 36, 1959.

6. Pereira, C. M. P.; Hobuss, C. B.; Maciel, J. V.; Ferreira, L. R.; Pino, F. B. D.; Mesko, M. F.; Jacob-Lopes, E.; Neto, P. C.; Quim. Nova 2012, 35, 2013.

7. Suali, E.; Sarbatly, R.; Renewable Sustainable Energy Rev. 2012, 16, 4316.

8. Spolaore, P.; Joannis-Cassan, C.; Duran, E.; Isambert, A.; J. Biosci. Bioeng. 2006, 101, 87.

9. He, C.; Chen, C. L.; Giannis, A.; Yang, Y.; Wang, J. Y.; Renewable Sustainable Energy Rev. 2014, 39, 1127.

10. http://microbiology.ucdavis.edu/meeks/BG11medium.html, accessed in May 2017.

11. Kasiri, S.; Ania, U.; Vinay, P.; Bioresour. Technol. 2015, 194, 144.

12. Karam, L. M.; Soccol, C. R.; Arq. Ciênc. Vet. Zoo. 2007, 10, 1,5 .

13. Carvalho, M. S.; Mendonça, M. A.; Pinho, D. M. M.; Resck, I. S.; Suarez, P. A. Z.; J. Braz. Chem. Soc. 2012, 23, 763.

14. Faria, R. C. M.; Rezende, M. J. C.; Rezende, C. M.; Pinto, A. C.; Quim. Nova. 2007, 30, 1900.

15. Martinez-Guerra, E.; Gude, V. G.; Mondala, A.; Holmes, W.; Hernandez, R.; Bioresour. Technol. 2014, 129, 354.

16. Qiang, L.; Lin, L.; Rong, C.; Xun, Z.; Bioresour. Technol. 2014, 161, 186.

17. Radmann, E. M.; Costa, J. A. V.; Quim. Nova 2008, 31, 7.

18. Fernandes, B. D.; Mota, A.; Ferreira, A.; Dragone, G.; Teixeira, J. A.; Vicente, A. A.; Chem. Eng. 2014, 117, 445.

19. Mandik, Y. I.; Cheirsilp, B.; Boonsawang, P.; Prasertsan, P.; Bioresour. Technol. 2015, 182, 89.

20. Singhasuwan, S; Choorit, W.; Sirisansaneeyakul, S.; Kokkaew, N.; Chisti, Y.; J. Biotechnol. 2015, 216, 169.

21. Phukan, M. M.; Chutia, R. S.; Konwar, B. K.; Kataki, R.; Appl. Energy 2011, 88, 3307.

22. Chiu, S.; Kao, C.; Chen, C.; Kuan, T.; Ong, S.; Lin, C.; Bioresour. Technol. 2008, 99, 3389.

23. Pinho, D. M. M.; Suarez, P. A. Z.; Rev. Virtual Quim. 2017, 9 , 39.
Submitted: January 26, 2017

Published online: May 30, 2017 